\title{
Reflorestamento e Sequestro de Carbono no Cerrado de Mato Grosso: Análise de Viabilidade Econômica
}

\section{Reforestation and Carbon Sequestration in the Savanna of Mato Grosso: Economic Viability Analysis}

\author{
Sirlene Gomes Pessoa* \\ Benedito Dias Pereira** \\ Regina Célia Carvalho***
}

\begin{abstract}
Resumo: Com adoção da taxa interna de retorno (TIR) como metodologia de análise econômica, investiga-se a viabilidade econômica da produção de 200 hectares das espécies de eucalipto mais cultivadas em Mato Grosso (urograndis, citriodora e camaldulensis), com três finalidades: sequestro de carbono, cultivo de madeira para geração de energia e produção conjunta (sequestro de carbono e cultivo de madeira) em municípios localizados no cerrado do Estado. Os projetos exclusivamente para sequestro de carbono revelaram-se economicamente inviáveis, diferentemente dos destinados exclusivamente para cultivo de madeira para geração de energia, além dos projetos com produção conjunta em determinados municípios, que exibiram viabilidade econômica.
\end{abstract}

Palavras-chave: Cultivo de eucalipto. Tecnologias limpas. Rentabilidade.

Abstract: With adoption of the internal rate of return (IRR) as a method of economic analysis, investigates the economic feasibility of production of 200 ha of Mato Grosso's most cultivated eucalyptus species (urograndis, citriodora, camaldulensis), with three purposes: carbon sequestration, cultivation of wood for energy generation and joint production (carbon sequestration and timber cultivation) in municipalities located in the savanna of the State. Projects exclusively for carbon sequestration proved uneconomical, unlike the intended strictly for cultivation of wood for energy generation, in addition to project with join production in certain municipalities, which showed economic viability.

\footnotetext{
* $\quad$ Mestra pelo Programa de Pós-Graduação em Agronegócios e Desenvolvimento Regional (UFMT). Professora do Centro Universitário de Várzea Grande (Univag). E-mail: sgpessoa@ufmt.br

* * Doutor em Economia Agrícola pelo Pimes (UFPE). Professor do Programa de Pós-Graduação em Agronegócios e Desenvolvimento Regional da Universidade Federal de Mato Grosso (UFMT). E-mail:bdp@terra.com.br

* * * Doutora em Economia Agrícola pelo PIMES (UFPE). Professora do Programa de Pós-Graduação em Agronegócios e Desenvolvimento Regional da Universidade Federal de Mato Grosso (UFMT). E-mail: arva3@ig.com.br
} 
Keywords: Eucalyptus cultivation. Clean technology. Profitability.

JEL Classification: Q56.

\section{Introdução}

Em busca de aumento da renda e do aprimoramento das ferramentas de gestão ambiental, além da produção agropecuária, o segmento rural de Mato Grosso vem ampliando as áreas destinadas ao reflorestamento: cultivando espécies nativas e exóticas, especialmente o eucalipto. Introduzida no estado a partir da década de 1980, MT conta atualmente com cerca de 50 mil hectares de áreas plantadas com essa espécie vegetal (SHIMIZU; KLEIN; OLIVEIRA, 2007).

Com a ratificação do Protocolo de Kyoto em 2005, imaginou-se que houvesse surgido a oportunidade de se ampliar a renda no campo através da adoção de formas sustentáveis de produção recorrentes a mecanismos de desenvolvimento limpo (MDL), porquanto proporcionam redução ou remoção da atmosfera de gases diretamente associados ao efeito estufa (GEE) e, ao mesmo tempo, geram créditos de carbono ao produtor (SOARES; OLIVEIRA, 2002; VENTURA; ANDRADE, 2009).

Em outras palavras, o gás carbônico $\left(\mathrm{CO}_{2}\right)$ removido ou sequestrado da atmosfera por intermédio da implementação de projetos florestais (florestamento ou reflorestamento) no âmbito do MDL pode ser transformado em títulos, temporários ou de longo prazo, denominados Reduções Certificadas de Emissões (tCER e 1CER), ${ }^{1}$ comercializados no mercado internacional de carbono (FINCO; RODRIGUES; RODRIGUES, 2006; CALIXTO; RIBEIRO, 2007).

O Conselho Executivo do MDL - vinculado à Organização das Nações Unidas (ONU) - é a instituição mundialmente responsável pela emissão desses títulos e pelo registro dos projetos florestais. No Brasil, em 1999, foi instituída a Comissão Interministerial de Mudança Global de Clima (CIMGC), ficando o Ministério de Ciência e Tecnologia (MCT) responsável pela presidência dessa comissão, pela recepção e, se for o caso, pela aprovação dos projetos, bem como pela submissão destes ao Conselho Executivo do órgão (PESSOA; CARVALHO; PEREIRA, 2008b; PAIXÃO et al., 2006).

Entretanto, não há ainda registro no Conselho Executivo do MDL (ONU) de projetos florestais brasileiros destinados ao sequestro de carbono, a despeito de as metodologias de pequena e grande escala para esses projetos já estarem concluídas. Por outro lado, os agentes do mercado de carbono se encontram otimistas com relação aos créditos provenientes de outras fontes, como biomassa, dejetos animais, aterros sanitários, etc. No cenário global, o Brasil ocupa o terceiro lugar

CER é o mesmo que RCE: denominação em inglês da expressão Certified Emission Reductions. 
na comercialização dos títulos oriundos de fontes não florestais, com redução de poluição equivalente a 36,4 milhões de $\mathrm{tCO}_{2} \mathrm{e} / \mathrm{ano}^{2}$ (PELEIAS et al., 2007).

Como ilustração, Nishi et al. (2005) elaboraram estudos relativos à viabilidade econômica de projetos florestais no âmbito do MDL em uma região de cerrado do estado de São Paulo. Investigações semelhantes foram elaboradas por Finco e Rezende (2007) na região norte do Pará e, por Maestri et al. (2004), no extremo sul da Bahia e no leste do Espírito Santo. Com foco na viabilidade econômica, contudo, não se tem conhecimento de projetos voltados ao sequestro florestal no âmbito do MDL em Mato Grosso.

Diante disso, objetiva-se identificar a rentabilidade do cultivo de 200 ha de eucalipto das espécies mais cultivadas no cerrado mato-grossense (urograndis, citriodora e camaldulensis) com três objetivos: sequestro de carbono, cultivo de madeira destinada à geração de energia e produção conjunta (sequestro de carbono e cultivo de madeira destinada à geração de energia). Optou-se pela área de 200 ha, posto que, de acordo com Shimizu, Klein e Oliveira (2007), essa é a dimensão média e modal do cultivo de eucalipto no cerrado do estado.

\section{Material e Método}

Adota-se a taxa interna de retorno (TIR) como metodologia de análise econômica para se aferir à rentabilidade do cultivo de eucalipto no âmbito do MDL. A TIR, como se sabe, exibe relação direta com outros indicadores que estimam a rentabilidade de projetos, como o valor presente líquido (VPL), além de viabilizar a comparação do resultado obtido com diferentes taxas de rentabilidade disponíveis no mercado (SOARES; CARVALHO; VALE, 2003).

A TIR estabelece a igualdade entre receitas, investimentos e custos. Mais detalhadamente, é interpretada como a taxa que torna nulo o VPL de fluxo de caixa, ou seja, é a taxa $i$ quando o VPL desse fluxo se iguala a zero, conforme consta na equação 1 .

$$
V P L=-C F O+\sum_{j=1}^{n} \frac{C F i}{(1+i)^{j}}=0
$$

em que VPL: valor presente líquido; $\mathrm{CF}_{\mathrm{o}}$ : investimento inicial; $\mathrm{CF}_{\mathrm{i}}$ : benefícios esperados nos anos $j$; $i$ : taxa interna de retorno; e $n$ : número de períodos do fluxo de caixa.

Adota-se a taxa de juros do Sistema Especial de Liquidação e Custódia (Selic) de 11,25\% a.a. como taxa de mínima atratividade (TMA). Em perspectiva geral, a TIR se constitui em limite da TMA, visto que se adota critério de decisão amplamente conhecido em análises afins: são economicamente viáveis os projetos que

Tonelada de carbono equivalente ano. 
registram TIR acima da TMA. Por oposto, os projetos com TIR menor que a TMA são considerados economicamente inviáveis. Nesse caso, o produtor incorre em custo de oportunidade por não ter investido na melhor alternativa, isto é, nessa circunstância cabe ao empresário assumir o custo de oportunidade do empreendimento por não ter alocado seus recursos à taxa mais rentável no conjunto das alternativas disponíveis no mercado.

Por oportuno, Oliveira e Ribeiro (2002) propõem que a TIR se constitua em ferramenta utilizável na avaliação de sustentabilidade microeconômica de projetos no âmbito do MDL. De acordo com esse raciocínio, ela indicaria o nível de mudança nos custos das emissões de carbono sequestrado em relação à linha de base do projeto. ${ }^{3}$ Os autores ainda sugerem a adoção de taxas de desconto sobre a ótica pública e privada para se avaliar o desempenho financeiro de projetos com e sem a geração de CER.

\subsection{Cultivo de Eucalipto no Cerrado de Mato Grosso}

A região de cerrado em Mato Grosso se estende por 35,97 milhões de hectares. A fração mato-grossense desse ecossistema responde por aproximadamente $16 \%$ de todo o cerrado brasileiro e por 39\% da extensão territorial do estado (PESSOA et al., 2008a), conforme se ilustra na Figura 1.

Figura 1 - Estado de Mato Grosso: áreas ocupadas pelo cerrado

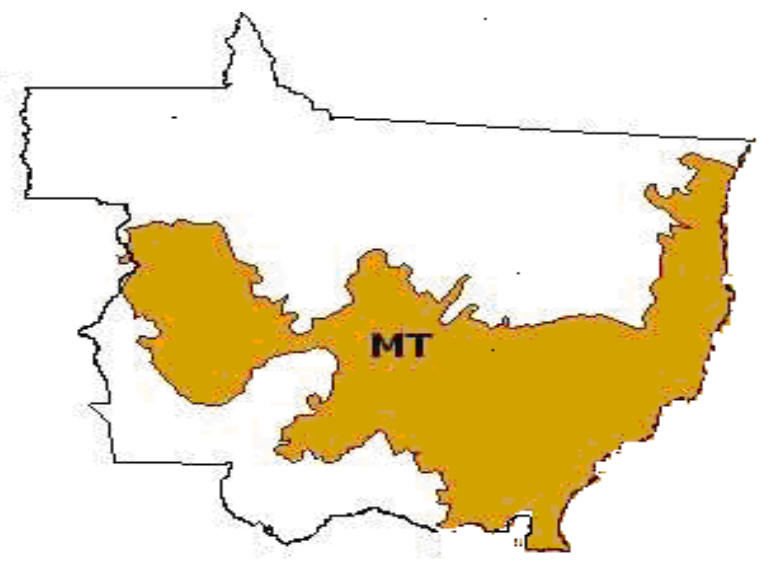

Fonte: Pessoa et al. (2008a).

Por sua vez, os 145,5 mil hectares de florestas plantadas no estado, segundo Shimizu, Klein e Oliveira (2007, p. 32), são majoritariamente constituídos pelas várias espécies de eucaliptos. A produção de eucalipto em Mato Grosso, insignificante frente aos 3,4 milhões de hectares cultivados no Brasil, está distribuída entre

3 A linha de base de um projeto de MDL é o cenário que representa, de maneira aproximada, as emissões antrópicas de GEE por fontes que ocorreriam na ausência da atividade proposta. 
as espécies híbridas e não híbridas, em que as espécies de maior área plantada são: urograndis (híbrida), citriodora e camaldulensis (não híbridas).

Os municípios com as maiores áreas plantadas com eucalipto em Mato Grosso são: Paranatinga, com 11.324 ha (citriodora), Dom Aquino, com 3.430 ha, Juscimeira, com 2.902 ha e Alto Araguaia, com 2.680 ha (urograndis), além de Rondonópolis, com 3.019 ha e Chapada dos Guimarães, com 1.298 ha (camaldulensis).

Por seu turno, o incremento médio anual (IMA) ou média anual de produtividade do eucalipto em Mato grosso gravita em torno de 23,28 para a espécie urograndis, 9,25 para a citriodora e 14,60 m/ha/ano para a camaldulensis. Esses valores variam em função da espécie cultivada, da eficiência hídrica da região e da fertilidade do solo, entre outras variáveis menos relevantes, conforme destacam Shimizu, Klein e Oliveira (2007). Como ilustração, o regime de produção e rebrota do eucalipto viabiliza até três rotações sucessivas, com colheita em torno de sete anos e reforma depois de 21 anos do plantio (NISHI et al., 2005).

\subsection{Sequestro de Carbono, Custos e Receita}

Para se estimar $\mathrm{O}_{2}$ que pode ser sequestrado pela planta, inicialmente quantifica-se o volume de biomassa nela existente, que, por sua vez, se relaciona diretamente com sua produtividade ou IMA. Para se calcular o teor de carbono da biomassa, vários pesquisadores, como Tsukamotto (2003) e Maestri et al. (2004), adotaram o fator 0,5 ou $50 \%$ de seu peso seco, então considera-se que a metade desse peso é constituído de carbono. Em seguida, para se quantificar a quantidade de $\mathrm{CO}_{2}$ sequestrada, o volume de carbono obtido é multiplicado pelo fator 3,67.4 Nessas condições, uma emissão de $1 \mathrm{GtC}$ (gigatonelada de carbono) é equivalente a $3,67 \mathrm{GtCO}_{2}$.

Por outro lado, a metodologia AR-AM0005 aprovada pelo Conselho Executivo do MDL para a elaboração de projetos do MDL permite estimar a remoção líquida de GEE por sequestro de reservatórios de biomassa viva acima e abaixo do solo. Com base nessa metodologia, para se estimar o sequestro de $\mathrm{CO}_{2}$ do eucalipto, por exemplo, Rezende e Serrano (2007) vêm adotando fatores de conversão que incluem a biomassa viva da parte aérea e das raízes da planta também com recorrência a fatores que abatem a linha de base e as fugas de GEE, estimando o sequestro líquido de $\mathrm{CO}_{2}$, com adoção da equação 2.

$$
\operatorname{IMA}\left(\mathrm{m}^{3}\right) \times 0,5_{\mathrm{a}} \times 0,5_{\mathrm{b}} \times 3,67 \times 1,3 \times 0,8
$$

em que IMA: produtividade de biomassa da planta em ha/ano $/ \mathrm{m}^{3} ; 0,5_{a}$ : fator de conversão de $\mathrm{m}^{3}$ de biomassa em toneladas (madeira seca); 0,5 : fator de conver-

Esse fator foi dimensionado pela relação $\mathrm{CO}_{2} / \mathrm{C}$ ou $44 / 12$, que, respectivamente, indicam o peso molecular do $\mathrm{CO}_{2}$ e do carbono (FINCO; RODRIGUES; RODRIGUES, 2006). 
são da biomassa em carbono (C); 3,67: fator de conversão do $\mathrm{C}_{\text {em }} \mathrm{CO}_{2}$, 1,3: valor de $\mathrm{C}$ atribuído à raiz da planta; e 0,8: fator que considera abate de $20 \%$ à linha de base (baseline) e às fugas (leakages).

A remoção líquida de $\mathrm{CO}_{2} /$ ha/ano pelo eucalipto foi estimada para os 200 ha hipoteticamente cultivados no decorrer de 20 anos. Esses valores foram aferidos em municípios onde são conhecidos os valores dos IMA's concernentes às espécies mais cultivadas, dentre elas, reafirmando-se: urograndis, citriodora e camaldulensis.

Foi utilizada apenas uma planilha para cômputo dos custos de produção para todos os municípios e espécies investigadas. Essa planilha foi elaborada com os subsídios de pesquisa elaborada no mercado local de preços de insumos usados na produção de eucalipto no cerrado, dentre eles, calcário, adubo, fosfato, formicida, herbicida, mudas, transporte, etc. Após a pesquisa, a planilha teve seu prazo estendido para 20 anos, contemplando-se as três rotações sucessivas da produção de eucalipto, adequando-a, portanto, a um dos períodos de creditação permitido pelo Protocolo de Kyoto.

Quanto aos custos do projeto de MDL (elaboração, monitoramento, certificação, registro junto à ONU, emissão de 1CER, etc.), foram elaboradas planilhas específicas para as três espécies em cada município, com base em proposta de projeto A/R. ${ }^{5}$ Por seu turno, para se estimar as receitas com carbono, adotou-se o preço de US $\$ 10,00 \mathrm{t} / \mathrm{CO}_{2}$ e com o valor do dólar cotado na moeda interna a $\mathrm{R} \$$ 1,77, em 22 de novembro de 2007.

\section{Resultados e Discussão}

A metodologia utilizada para estimativa de sequestro de carbono considera constante a quantidade de $\mathrm{CO}_{2}$, fato que leva o volume de ICER a também ser invariável. Nesses termos, anotam-se, na Tabela 1, os seguintes dados sobre o cultivo de 200 ha de três espécies de eucalipto (urograndis, citriodora, camaldulensis) em municípios situados no cerrado de Mato Grosso: estimativas do IMA e do sequestro de carbono para as três espécies e das receitas com 1CER, valores da conversão do IMA em metro estéreo (mst), além das receitas com crédito de carbono e com cultivo de madeira destinadas à geração de energia.

$5 \quad$ Refere-se em inglês a "afforestation and reforestation", ou seja, aos procedimentos adotados pelo Protocolo de Kyoto para os projetos de MDL de florestamento e reflorestamento (REZENDE; SERRANO, 2007). 
Tabela 1 - Cultivo de 200 ha de três espécies de eucalipto em municípios no cerrado de Mato Grosso: incremento médio anual (IMA), sequestro de $\mathrm{CO}_{2}$, receita com lCER, valores da conversão do IMA para mst, receita com créditos de carbono e receita com cultivo de madeira (geração de energia)

\begin{tabular}{|c|c|c|c|c|c|c|c|c|c|}
\hline \multirow{2}{*}{$\begin{array}{l}\text { Espécie } \\
\text { de } \\
\text { eucalipto }\end{array}$} & \multirow{2}{*}{$\begin{array}{c}\text { Município } \\
\text { localizado no } \\
\text { cerrado de Mato } \\
\text { Grosso }\end{array}$} & \multirow{2}{*}{$\begin{array}{c}\text { Incremento } \\
\text { médio anual } \\
\text { (IMA) } \\
\left({ }^{*}\right)\end{array}$} & \multicolumn{2}{|c|}{$\begin{array}{l}\text { Sequestro de } \mathrm{CO}_{2} \\
\text { (20 anos) }\end{array}$} & \multirow{2}{*}{$\begin{array}{c}\begin{array}{c}\text { Receita } \\
\text { com } \\
\text { ICER } \\
(* *)\end{array} \\
\\
(\mathbf{R} \$ \\
1000,00)\end{array}$} & \multicolumn{2}{|c|}{$\begin{array}{l}\text { IMA } \\
\text { (mst) }\end{array}$} & \multirow{2}{*}{$\begin{array}{l}\text { Receita } \\
\text { com } \\
\text { créditos } \\
\text { de } \\
\text { carbono } \\
(\mathbf{R} \$ \\
1000,00)\end{array}$} & \multirow{2}{*}{$\begin{array}{c}\text { Receita } \\
\text { com } \\
\text { cultivo de } \\
\text { madeira } \\
\text { (geração } \\
\text { de } \\
\text { energia) } \\
(\mathrm{R} \$ \\
1000,00)\end{array}$} \\
\hline & & & $\begin{array}{c}(1000 \\
t / \\
\text { ha/ } \\
\text { ano })\end{array}$ & $\begin{array}{c}1000 \mathrm{t} / \\
200 \mathrm{ha})\end{array}$ & & $\begin{array}{l}\text { (ha/ } \\
\text { ano) }\end{array}$ & $\begin{array}{c}(200 \\
\text { ha/ } \\
20 \\
\text { anos) }\end{array}$ & & \\
\hline \multirow{4}{*}{ Urograndis } & Campo Verde & 39 & 37 & 147 & 2.617 & 5,41 & 221.640 & 699 & 6.649 \\
\hline & $\begin{array}{c}\text { Chapada dos } \\
\text { Guimarães }\end{array}$ & 10 & 9 & 39 & 699 & 14,81 & 59.240 & 2.617 & 1.777 \\
\hline & Dom Aquino & 33 & 31 & 125 & 2.228 & 47,16 & 188.640 & 2.228 & 5.659 \\
\hline & Sorriso & 18 & 17 & 68 & 1.206 & 25,52 & 102.080 & 1.205 & 3.062 \\
\hline Citriodora & Campo Verde & 20 & 18 & 75 & 1.336 & 28,30 & 113.200 & 1.336 & 3.396 \\
\hline \multirow{6}{*}{ Camaldulensis } & Chapada dos & 3 & 19 & 11 & 202 & 4,27 & 17.080 & 1,38 & 512 \\
\hline & Guimarães & 17 & 16 & 66 & 1.170 & 24,77 & 99.080 & 1.170 & 2.972 \\
\hline & $\begin{array}{l}\text { Cuiabá } \\
\text {. }\end{array}$ & 22 & 20 & 83 & 1.474 & 31,20 & 124.800 & 1.474 & 3.744 \\
\hline & $\begin{array}{l}\text { Dom Aquino } \\
\text { Nossa Senhora do }\end{array}$ & 16 & 15 & 62 & 1.099 & 23,27 & 93.080 & 1.099 & 2.792 \\
\hline & Livramento & 8 & 8 & 33 & 586 & 12,41 & 49.640 & 586 & 1.489 \\
\hline & $\begin{array}{l}\text { Rondonópolis } \\
\text { Sorriso }\end{array}$ & 20 & 3 & 78 & 1.385 & 29,33 & 117.320 & 202 & 3.519 \\
\hline
\end{tabular}

Fonte: Elaboração própria.

Nota: * Estimado por Shimizu, Klein e Oliveira (2007); ** $\mathrm{lCER}=\mathrm{R} \$ 17,70$.

A quantidade de $\mathrm{CO}_{2} / \mathrm{ha} /$ ano sequestrada pelo eucalipto varia em função do IMA, que, por sua vez, oscila de acordo com a espécie e a região onde está sendo cultivado (solo, clima, pluviometria, etc.). Quanto ao cálculo da receita com madeira para geração de energia, utilizou-se o IMA -medido em metro estéreo- como unidade de medida, considerando-se que $1,00 \mathrm{~m}^{3}$ de madeira corresponde a 1,43 mst. Os IMAs em metro estéreo - ao preço de outubro de 2007 - foram valorados a R\$ 30,00 por árvore em pé (PESSOA et al., 2008a).

Foi pressuposto que a comercialização de madeira ocorre em três momentos: no $6^{\circ}$ ano, no $13^{\circ}$ ano, e, a última, no $20^{\circ}$ ano. Portanto, os fluxos de caixa foram elaborados com base na receita de crédito de carbono do $5^{\circ}, 10^{\circ}, 15^{\circ}$ e $20^{\circ}$ mês e na receita de madeira do $6^{\circ}, 13^{\circ}$ e $20^{\circ}$ mês. Como ilustração, no Apêndice A consta exemplo de fluxo de caixa para crédito de carbono, cultivo de madeira e produção conjunta (crédito de carbono e cultivo de madeira) em 200 ha de eucalipto, hipoteticamente cultivados no município de Campo Verde.

Observa-se que o projeto cultivado com a espécie urograndis sequestra maior quantidade de $\mathrm{CO}_{2}$ em Campo Verde, enquanto a menor quantidade sequestrada foi presenciada em Chapada dos Guimarães. O projeto com o cultivo da espécie citriodora sequestra $75.000 \mathrm{t}$ de $\mathrm{CO}_{2}$ em Campo Verde, equivalente a $\mathrm{R} \$ 1.336 .000,00$. Por seu turno, o projeto com a espécie camaldulensis sequestra a maior quantidade de $\mathrm{CO}_{2}$ em Dom Aquino, enquanto a menor quantidade ocorre em Chapada dos Guimarães. 
O valor da receita gerada pelo cultivo de madeira (geração de energia) é dependente do IMA de cada povoamento. Logo, como as maiores produtividades estão vinculadas ao cultivo da espécie urograndis, obtidas, sequencialmente, em Campo Verde e Dom Aquino, as receitas mais elevadas são exibidas por essas grandezas. Em contraste, sincronizada com a menor das produtividades, a receita menos expressiva foi obtida no projeto com o cultivo da espécie camaldulensis em Chapada dos Guimarães.

Como se adota a Selic (valor a 11,25\%) como taxa de mínima atratividade, relembra-se que essa grandeza se constitui em custo de oportunidade para a decisão do segmento rural de empreender, ou não, o projeto. Com recorrência à planilha Excel, com o uso da equação 2, contemplando-se as três alternativas de projetos de cultivo de 200 ha de eucalipto. As taxas internas de retorno estimadas estão resumidas na Tabela 2, na qual também constam os custos médios de reflorestamento, assim como os custos dos projetos no âmbito do MDL.

Tabela 2 - Cultivo de 200 ha de três espécies de eucalipto no cerrado de Mato Grosso: custo médio com reflorestamento, custos com projeto (MDL) e TIR para créditos de carbono, cultivo de madeiras (energia) e produção conjunta (sequestro de carbono e cultivo de madeiras)

\begin{tabular}{|c|c|c|c|c|c|c|}
\hline \multirow[b]{2}{*}{ Espécie } & \multirow[b]{2}{*}{ Municipio } & \multirow[b]{2}{*}{$\begin{array}{c}\text { Custo médio com } \\
\text { reflorestamento } \\
(\mathrm{R} \$ 1.000,00)\end{array}$} & \multirow[b]{2}{*}{$\begin{array}{c}\text { Custo com } \\
\text { projeto de } \\
\text { MDL } \\
\text { (R\$ } 1.000,00)\end{array}$} & \multicolumn{3}{|c|}{ TIR (\%) } \\
\hline & & & & $\begin{array}{l}\text { Créditos } \\
\text { de } \\
\text { carbono }\end{array}$ & $\begin{array}{l}\text { Cultivo de } \\
\text { madeiras } \\
\text { (energia) }\end{array}$ & $\begin{array}{c}\text { Produção } \\
\text { conjunta } \\
\text { (sequestro } \\
\text { de } \\
\text { carbono e } \\
\text { cultivo de } \\
\text { madeiras) }\end{array}$ \\
\hline Urograndis & $\begin{array}{c}\text { Chapada dos } \\
\text { Guimarães } \\
\text { Campo Verde } \\
\text { Dom Aquino } \\
\text { Sorriso }\end{array}$ & $\begin{array}{l}1.139 \\
1.139 \\
1.139 \\
1.139\end{array}$ & $\begin{array}{l}1.013 \\
1.174 \\
1.141 \\
1.054\end{array}$ & $\begin{array}{c}(-) \\
2,35 \\
(-) \\
(-)\end{array}$ & $\begin{array}{r}5,24 \\
24,21 \\
21,47 \\
12,22\end{array}$ & $\begin{array}{c}2,48 \\
24,90 \\
21,89 \\
11,34\end{array}$ \\
\hline Citriodora & Campo Verde & 1.139 & 1.064 & $(-)$ & 13,66 & 13,04 \\
\hline Camaldulensis & $\begin{array}{l}\text { Chapada dos } \\
\text { Guimarães } \\
\text { Cuiabá } \\
\text { Dom Aquino } \\
\text { Nossa Senhora do } \\
\text { Livramento } \\
\text { Rondonópolis } \\
\text { Sorriso }\end{array}$ & $\begin{array}{l}1.139 \\
1.139 \\
1.139 \\
\\
\\
1.139 \\
1.139 \\
1.139\end{array}$ & $\begin{array}{c}973 \\
1.051 \\
1.077 \\
\\
\\
1.045 \\
1.004 \\
1.065\end{array}$ & $\begin{array}{l}(-) \\
(-) \\
(-) \\
\\
(-) \\
(-) \\
(-)\end{array}$ & $\begin{array}{c}(-) \\
11,81 \\
15,06 \\
\\
10,97 \\
3,12 \\
14,17\end{array}$ & $\begin{array}{c}(-) \\
10,85 \\
14,66 \\
\\
9,84 \\
(-) \\
13,63\end{array}$ \\
\hline
\end{tabular}

Fonte: Elaboração própria.

Nota: (-) TIR negativa.

Quanto ao projeto no âmbito do MDL, os custos dessa etapa representaram aproximadamente $50 \%$ dos custos totais, variando para cada espécie e em cada município em função da quantidade de carbono sequestrada. Para a espécie urograndis, esses custos ficaram acima do custo médio de reflorestamento em Campo Verde e em Dom Aquino. A espécie citriodora em Campo Verde teve custos de 
MDL inferior ao custo médio de reflorestamento. Quanto ao cultivo com a espécie camaldulensis, vê-se que todos os custos médios com reflorestamento suplantam os respectivos custos no âmbito do MDL. Observa-se que a inserção do projeto no âmbito do MDL também exige a projeção dos custos de reflorestamento.

Verifica-se, na Tabela 2, que, quando se produz eucalipto somente para fins de sequestro de carbono, as taxas internas de retorno exibem grandezas negativas em todos os municípios com o cultivo das três espécies, exceto em Campo Verde, que assume o valor de 2,35\% a.a., posicionando-se bem abaixo da TMA, dessa maneira inviabilizando economicamente o projeto. Um dos fatores que contribuíram para a obtenção desses valores, por um lado, deve ser imputado ao alto custo do reflorestamento em Mato Grosso em decorrência de exigências do corrente elevado nível tecnológico adotado no cultivo dessa espécie, por outro lado, no caso específico da citriodora, as receitas de carbono e madeira proveem de povoamentos cultivados a partir da década de 1990, e até da de 1980, logo, implicando na adoção de tecnologias com baixa produtividade.

Em especial, o baixo IMA em alguns municípios como Chapada dos Guimarães e Rondonópolis conduziu a um reduzido sequestro de $\mathrm{CO}_{2}$, que, por seu turno, contribuiu para a contração da receita obtida com créditos de carbono e, consequentemente, atuando para que a TIR estimada fosse negativa. Outros fatores, como o alto custo do projeto de MDL e o baixo preço da lCER, também contribuíram para esse resultado.

A equiparação do preço da ICER ao preço dos demais títulos de carbono (não florestais) poderia alterar esse cenário, entretanto, incorrer-se-ia em alto risco se investir com essa expectativa pelos seguintes fatos: a) o mercado de títulos provenientes do sequestro florestal foi limitado pelo Protocolo de Kyoto em $1 \%$ x 5 , ou seja, 1\% do total de poluição (1990) de cada país relacionado no Anexo I desse Protocolo, multiplicado pelo número de anos do primeiro período de compromisso do Protocolo (2008 a 2012); b) os países ofertantes de lCER também concorrem com o mercado doméstico de países do Anexo I e com outros títulos de carbono (não florestais); c) a fixação de prazo de vencimento dos títulos florestais atuou como redutor da rentabilidade do mercado, uma vez que os demais títulos de carbono são operados com tempo indeterminado.

Com relação à análise da produção de eucalipto somente para extração de madeira para geração de energia - sem a comercialização de lCERs, conquanto algumas taxas internas terem registrado valores inferiores à TMA -, foi positiva nos projetos com as três espécies em todos os municípios, exceto com a camaldulensis em Chapada dos Guimarães.

Em particular, os projetos destinados ao cultivo de madeira com a espécie urograndis em Campo Verde, Dom Aquino e Sorriso, com a citriodora em Campo Verde e com a camaldulensis em Cuiabá, Dom Aquino e Sorriso registraram TIR 
acima da TMA. As taxas dos projetos com a espécie urograndis se destacam positivamente em Campo Verde $(24,21 \%)$ e Dom Aquino (21,47\%). Como em todos esses casos as taxas também excedem a TMA, deduz-se que, mesmo sem a comercialização do carbono sequestrado, esses projetos são economicamente viáveis.

Por sua vez, a análise da produção conjunta (sequestro de carbono e cultivo de madeira para geração de energia) exibe TIR acima e abaixo da TMA, bem como valores negativos. As grandezas mais elevadas (24,90\% e 21,89\% a.a.), superiores à TMA, derivam de cultivos com a espécie urograndis, respectivamente, em Campo Verde e em Dom Aquino. Além desses, enquanto alguns valores também superam a TMA, a despeito de serem positivas, outros são menores que essa métrica, nesse caso juntamente com os valores negativos da TIR, inviabilizando economicamente os projetos.

\section{Considerações Finais}

A produção de eucalipto para fins somente de sequestro de carbono exibiu taxa interna de retorno negativa em projetos supostamente empreendidos nos municípios contemplados na pesquisa, com exceção do cultivo com urograndis em Campo Verde, onde a taxa interna foi de $2,35 \%$, inferior, portanto, à taxa de mínima atratividade. Diante disso, infere-se que esses projetos são economicamente inviáveis.

Quanto à produção apenas de madeira destinada à geração de energia, os projetos com as três espécies registraram taxas internas positivas e acima da taxa mínima de atratividade em Campo Verde, Dom Aquino e Sorriso (espécie urograndis), em Campo Verde (espécie citriodora) e em Cuiabá, Dom Aquino e Sorriso (espécie camaldulensis). Logo, nesses casos, os projetos revelaram viabilidade econômica.

Por sua vez, os projetos com o cultivo das três espécies para produção conjunta (sequestro de carbono e cultivo de madeira para geração e energia) exibiram taxas internas acima da taxa mínima de atratividade em Campo Verde, Dom Aquino e Sorriso (espécie urograndis), em Campo Verde (espécie citriodora) e em Dom Aquino e Sorriso (espécie camaldulensis). Por fim, verificou-se redução da rentabilidade relativa desses projetos, pois os com produção exclusivamente com madeira, em média, foram mais rentáveis.

\section{Referências}

CALIXTO, J. S.; RIBEIRO, A. E. M. Três olhares sobre o reflorestamento: a percepção de atores sociais sobre a monocultura de eucalipto no Alto Jequitinhonha, MG. Organizações Rurais $\mathcal{E}$ Agroindustriais, Lavras, v. 9, n. 3, p. 437-449, 2007. 
FINCO, M. V. A.; REZENDE, D. O. Mecanismo de desenvolvimento limpo (MDL) como gerador de benefícios econômicos: uma estimativa para o Município de Cumaru do NortePA. Revista Científica do Instituto Ecológica, Palmas, v. 1, n. 1, p. 45-58, 2007.

FINCO, M. V. A.; RODRIGUES, W.; RODRIGUES, I. A Amazônia legal brasileira e mercado de créditos de carbono: perspectivas para o Estado de Tocantins. Amazônia: Ciência 8 Desenvolvimento, Belém, v. 2, n. 3, p. 7-24, 2006.

MAESTRI, R.; SANQUETTA, C. R.; MACHADO S. A.; SCOLFORO, J. R. S.; CORTE, A. P. D. Viabilidade de um projeto florestal de eucalyptus grandis considerando o sequestro de carbono. Floresta, Curitiba, v. 34, n. 3, p. 347-360, 2004.

NISHI, M. H.; JACOVINE, L. A. G.; SILVA, M. L.; VALVERDE, S. R.; NOGUEIRA, H. P.; ALVARENGA, A. P.; Influência dos créditos de carbono na viabilidade financeira de três projetos florestais. Áruore, Viçosa, v. 29, n. 5, p. 76-88, 2005.

OLIVEIRA, A. S.; RIBEIRO, L. S.; Proposta revisada de critérios e indicadores de elegibilidade para avaliação de projetos candidatos ao MDL. MMA, abr. 2002. Disponível em: <http://www. centroclima.org.br/ccpdf/ criterio. pdf>. Acesso em: 19 nov. 2007.

PAIXÃO, F. A.; SOARES, C. P. B.; JACOVINE, L. A. G.; SILVA, M. L.; LEITE, H. C.; SILVA, G. F.; Quantificação do estoque de carbono e avaliação econômica de diferentes alternativas de manejo em um plantio de eucalipto. Áruore, Viçosa, v. 30, n. 3, p. 411-420, 2006.

PELEIAS, I. R.; NELSON, S. B.; ROCHA, M. T.; PEREIRA, A. C.; SEGRETI, B. C.; Tratamento contábil dos projetos de crédito de carbono no Brasil: um estudo exploratório. Gestão Social e Ambiental, Salvador, v. 1, n. 3, p. 79-98, 2007.

PESSOA, S. G.; FIGUEIREDO, A. M. R.; FILHO, A. O.; BONJOUR, S. C. M.; Quantificação da área disponível para sequestro de carbono no Bioma Amazônia em Mato Grosso. Amazônia: Ciência 8 Desenvolvimento, Belém, v. 3, n. 6, p. 237-247, 2008 a.

PESSOA, S. G.; CARVALHO, R. C.; PEREIRA, B. D; Mecanismos de mercado de carbono disponíveis ao segmento rural Mato-grossense. Organizações Rurais $\mathcal{E}$ Agroindustriais, Lavras, V. 1, n. 10, p. 102-112, 2008b.

REZENDE, D. J. C.; SERRANO, D. Proposta de projeto A/R. São Paulo: Ecológica Assessoria, 2007. 1 CD Rom.

SHIMIZU, J. Y.; KLEIN, H.; OLIVEIRA, J. R. V. Diagnóstico das plantações florestais em Mato Grosso. Cuiabá: Central de Texto, 2007.

SOARES, C. P.; OLIVEIRA, M. L. R. Equações para estimar quantidade de carbono na parte aérea de Árvores de eucalipto em Viçosa, Minas Gerais. Áruore, Viçosa, v. 26, n. 5, p. 533539, 2002.

SOARES, T. S.; CARVALHO, R. M. M. A.; VALE, A. B. Avaliação econômica de um povoamento eucalyptus grandis destinado a multiprodutos. Árvore, Viçosa, v. 27, n. 5, p. 67-80, 2003.

TSUKAMOTO, A. A. Fixação de carbono em um sistema agroflorestal com eucalipto na região do Cerrado de Minas Gerais. 99 f. Tese (Doutorado em Ciência Florestal) - Universidade Federal de Viçosa, Viçosa, 2003.

VENTURA, A. C.; ANDRADE, J. C. S. Conflitos socioambientais envolvendo projetos de mecanismo de desenvolvimento limpo (MDL) na América Latina. Gestão Social Ambiental, Salvador, v. 3, n. 3, Edição Especial, p. 86-98, 2009. 
Apêndice A - Fluxo de caixa: crédito de carbono, cultivo de madeira e produção conjunta (crédito de carbono e cultivo de madeiral em $200 \mathrm{ha}$ de eucalipto cultivados em Campo Verde (município do cerrado de Mato Grosso) (R $\$ 1,00)$

\begin{tabular}{|c|c|c|c|c|c|c|c|c|c|}
\hline \multicolumn{7}{|c|}{ Espécie de eucalipto: urograndis } & \multirow{2}{*}{\multicolumn{3}{|c|}{ Fluxo de caixa }} \\
\hline \multicolumn{7}{|c|}{ Sequestro de $\mathrm{CO}_{2}: 36,97 \mathrm{t} / \mathrm{ha} / \mathrm{ano}$; IMA: $55,41 \mathrm{mst} / \mathrm{ha} / \mathrm{ano}$} & & & \\
\hline Anos & $\begin{array}{l}\text { Custo } \\
\text { projeto } \\
\text { de MDL }\end{array}$ & $\begin{array}{c}\text { Custo } \\
\text { médio } \\
\text { (produção } \\
\text { de } \\
\text { eucalipto) }\end{array}$ & $\begin{array}{c}\text { Custo } \\
\text { total }\end{array}$ & $\begin{array}{c}\text { Receita } \\
\text { de } \\
\text { crédito } \\
\text { de } \\
\text { carbono }\end{array}$ & $\begin{array}{c}\text { Receita do } \\
\text { cultivo de } \\
\text { madeira }\end{array}$ & $\begin{array}{c}\text { Receita } \\
\text { total }\end{array}$ & $\begin{array}{l}\text { Crédito } \\
\text { de } \\
\text { carbono }\end{array}$ & $\begin{array}{c}\text { Cultivo } \\
\text { de } \\
\text { madeira }\end{array}$ & $\begin{array}{l}\text { Crédito } \\
\text { de }\end{array}$ \\
\hline 0 & 106.200 & 521.914 & 628.114 & 0 & 0 & 0 & -628.114 & -521.914 & -628.114 \\
\hline 1 & 1.303 & 97.686 & 98.989 & 0 & 0 & 0 & -98.989 & -97.686 & -98.989 \\
\hline 2 & 0 & 95.686 & 95.686 & 0 & 0 & 0 & -95.686 & -95.686 & -95.686 \\
\hline 3 & 0 & 12.586 & 12.586 & 0 & 0 & 0 & -12.586 & -12.586 & -12.586 \\
\hline 4 & 0 & 12.586 & 12.586 & 0 & 0 & 0 & -12.586 & -12.586 & -12.586 \\
\hline 5 & 177.000 & 12.586 & 189.586 & 0 & 0 & 0 & -189.586 & -12.586 & -189.586 \\
\hline 6 & 89.694 & 13.832 & 103.526 & 654.369 & 1.994 .760 & 2.649 .120 & 550.842 & 1.980 .927 & 2.545 .602 \\
\hline 7 & 0 & 38.886 & 38.886 & 0 & 0 & 0 & -38.886 & -38.886 & -38.886 \\
\hline 8 & 0 & 38.886 & 38.886 & 0 & 0 & 0 & -38.886 & -38.886 & -38.886 \\
\hline 9 & 0 & 12.586 & 12.586 & 0 & 0 & 0 & -12.586 & -12.586 & -12.586 \\
\hline 10 & 177.000 & 12.586 & 189.586 & 0 & 0 & 0 & -189.586 & -12.586 & -189.586 \\
\hline 11 & 89.694 & 12.586 & 102.280 & 654.369 & 0 & 654.369 & 552.088 & -12.586 & 552.088 \\
\hline 12 & 0 & 12.586 & 12.586 & 0 & 0 & 0 & -12.586 & -12.586 & -12.586 \\
\hline 13 & 0 & 13.832 & 13.832 & 0 & 2.327 .220 & 2.327 .220 & -13.832 & 2.313 .387 & 2.313 .387 \\
\hline 14 & 0 & 83.886 & 83.886 & 0 & 0 & 0 & -83.886 & -83.886 & -83.886 \\
\hline 15 & 177.000 & 83.886 & 260.886 & 0 & 0 & 0 & -260.886 & -83.886 & -260.886 \\
\hline 16 & 89.694 & 12.586 & 102.280 & 654.369 & 0 & 654.369 & 552.088 & -12.586 & 552.088 \\
\hline 17 & 0 & 12.586 & 12.586 & 0 & 0 & 0 & -12.586 & -12.586 & -12.5861 \\
\hline 18 & 0 & 12.586 & 12.586 & 0 & 0 & 0 & -12.586 & -12.586 & -12.586 \\
\hline 19 & 0 & 12.586 & 12.586 & 0 & 0 & 0 & -12.586 & -12.586 & -12.586 \\
\hline 20 & 266.694 & 12.586 & 279.280 & 654.369 & 2.327 .220 & 2.981 .589 & 375.088 & 2.314 .633 & 2.702 .308 \\
\hline Total & 1.174 .279 & 1.139 .530 & 2.313 .811 & 2.617 .476 & 6.649 .200 & 9.266 .676 & 303.664 & 5.509 .660 & 6.952 .864 \\
\hline VPL & & & & & & & -155 & $-24,91$ & $-16,51$ \\
\hline TIR & & & & & & & $2,35 \%$ & $24,21 \%$ & $24,90 \%$ \\
\hline
\end{tabular}

Fonte: Elaboração própria.

Recebido em: 31/12/2010.

Aceito em: 20/05/2013. 